\title{
Engineering lecturers' views on CLIL and EMI
}

\author{
Marta Aguilar \\ Faculty of Engineering (ETSEIB), Universitat Politècnica de Catalunya, Barcelona, Spain
}

\begin{abstract}
The present study aims to shed some light on how engineering lecturers teaching in English at a Spanish university view their work (teaching goals) within the current European internationalisation trend of offering courses and master programmes in English. A questionnaire where content and language integrated learning (CLIL) and English-medium instruction (EMI) were differentiated and with questions on their self-attributed duties, training preferences, assessment and internationalisation issues, among others, was prepared. The 41 lecturers who participated were asked to identify the modality they were following and their views related to the key factors in their courses. Findings point to the fact that EMI is the modality they follow and that they do not want to shift to CLIL because they refuse to teach language. To gain qualitative information about their beliefs, six lecturers were later interviewed. These interviews suggested that lecturers attach no importance to language integration. More specifically, they do not usually reflect on their lecturing, they welcome the idea of distinguishing both modalities in higher education (HE), they regard English proficiency as a key factor for all stakeholders and finally they think CLIL better suits less proficient students in HE.
\end{abstract}

\section{ARTICLE HISTORY}

Received 13 August 2014

Accepted 6 July 2015

\section{KEYWORDS}

CLIL (content and language integrated learning); EMI (English-medium instruction); higher education; lecturer beliefs; multilingualism

\section{Introduction}

Over the past few years, schools and universities offering content and language integrated learning (CLIL) courses have mushroomed across Europe. Among factors that have fuelled this growing development we find the European general policy to promote a multilingual Europe (Eurydice 2006). In fact, multilingualism is considered to be a good 'means to provide the world's citizenry with varied lenses needed to capture, understand and create our global reality' (Skutnabb-Kangas 1995, 224-225) and to educate multilingual, multiliterate and multicultural professionals able to work and communicate in a globalised world (Skutnabb-Kangas 1995; García 2009). Other reasons point to the reported beneficial impacts of more intensive exposure to the foreign language through content teaching in front of formal instruction (Ruiz de Zarobe et al. 2011) and, in the case of European higher education (EHE), to the internationalisation drive. In the EHE, the implementation of internationalisation policies, mostly promoting mobility and qualification recognition, has contributed to an increasing offer of fully or partly English-taught masters, in particular in engineering and business programmes (Wächter and Maiworm 2008; Unterberger and Wihelmer 2011). The growth of these programmes is remarkable because the number of English-taught programmes has increased by 239\% between 2007 and 2014 (Wächter and Maiworm 2014). By and large, many EHE institutions offer international programmes as an added value that singles them out from other competing institutions and makes them more appealing and competitive (Smit and Dafouz 2012; Unterberger 2012). In turn, internationalisation has led to the Englishisation of many EHE 
programmes (Coleman 2006) because English has become the foreign language chosen by many European universities (Doiz, Lasagabaster, and Sierra 2011; Smit and Dafouz 2012). Bearing these factors in mind, the internationalisation trend can also be framed within a neo-liberal conception of education that envisages education as an investment bringing rewards to participants and institutions (Lasagabaster, Cots, and Mancho-Barés 2013).

Far from being a unique formula, CLIL is an umbrella term encompassing a wide variety of foci across educational institutions and countries and is commonly used as a synonym to Englishmedium instruction (EMI) in higher education (HE). The need of shedding some light on the myriad of foci has been identified (Smit and Dafouz 2012) because, 'the rapid spread of CLIL has outpaced measures of its impact' (Pérez-Cañado 2012, 316). In the case of Spain, 'EMI programmes have paradoxically operated from a bottom-up perspective, with individual teachers or departments embarking in EMI on an experimental level' (Dafouz, Camacho, and Urquía 2014, 227), thus leaving important decisions to lecturers. That being so, it becomes necessary to know how lecturers integrate language when lecturing in English, what their self-allocated duties are and whether they are able to articulate these on the level of explicit reflection and knowledge. In a word, inquiring into lecturer beliefs seems a necessary previous step for teacher training design and even for sound internationalisation policy-making.

The rapid pace of internationalisation and the different labels (for example CLIL or EMI) one can find in the literature reveal that little is known about how international programmes are actually being implemented. This small-scale study aims to probe engineering lecturers' beliefs as regards CLIL and EMI and their actual teaching practices, and tries to unveil their views on their role as English-medium content teachers at universities that were at the beginning of their internationalisation process. The first research question quantitatively inquires into the modality engineering lecturers align themselves with and their beliefs regarding the role of English proficiency, the internationalisation process, their acknowledged academic duties or their willingness to receive methodological training. The second question seeks to understand why they hold these beliefs and how they respond to these themes. Although multiculturalism is another important intervening factor in this international setting, this issue falls beyond the scope of the study. The combination of both quantitative and qualitative methods should help us attain the overall goal of the study, that is, elicit lecturer beliefs in terms of explicit reflection and gain knowledge about how CLIL/EMI are viewed and implemented by the lecturers in the study.

\section{CLIL vs. EMI in Higher Education}

As said above, research on CLIL and EMI and their actual practices in HE is insufficient, and only recently has the first conceptualisation of English-medium education in multilingual university settings appeared (Dafouz and Smit 2014). Divergent and inconclusive results in CLIL research at primary and secondary levels, mainly arising from some methodological flaws, have been pointed out (Bruton 2011; Bonnet 2012), which means that some results should be compared and interpreted with caution (Pérez-Cañado 2012). At university level, though, the problem might lie in the heterogeneous contexts under study. A quick look at the methodology section in much research on $\mathrm{HE}$ reveals that different contexts have been analysed as CLIL when in fact they were non comparable. CLIL implementation in HE is highly variegated and as a result, the literature review in much research does not usually distinguish the exact type of instructional setting in which the results were obtained. More often than not, CLIL and EMI are used indistinctively to describe HE learning settings, wrongly assuming that it is only a question of diffuse labelling. Smit and Dafouz solve the 'terminological dilemma' $(2012,4)$ by suggesting that practices lacking the fusion of two pedagogical teaching aims (language and content) do not fall into the CLIL or integrating content and language (ICL) category and suggest the type of research focus as a defining criterion for EMI and ICL. In other instances, CLIL is associated with primary and secondary education research, whereas EMI, ICLHE and CLIL are frequent terms in $\mathrm{HE}$, leading us to the conclusion that 'a theory of practice is urgently 
needed' (Costa and D'angelo 2011, 11). Knowledge about the actual CLIL practices in EHE then seems necessary as well as knowledge about lecturers' willingness and attitudes towards a truthful language and content integrated approach.

One of the first attempts to unravel the wide array of foci used at tertiary level comes from Greere and Räsänen $(2008,6)$, who identified five main types of CLIL: (i) LSP (discipline-based language teaching by language specialists); (ii) Non-CLIL (a context with less than $25 \%$ of unsystematic and incidental exposure to the foreign language and no concern for language teaching); (iii) Pre-CLIL (content teaching with no specified language learning outcomes and more than $25 \%$ of exposure to the foreign language); (iv) Adjunct CLIL (tandem teaching with content and language specialists coordination and language integration) and (v) CLIL (a full dual integration of language across subject teaching). As argued below, in this study Non-CLIL and Pre-CLIL are fused and labelled EMI, whereas Adjunct CLIL and CLIL are considered to be CLIL (see Unterberger and Wihelmer 2011 for a similar and more detailed categorisation). At tertiary level, three other terms are also found in the literature. One is English as a Lingua Franca (ELF), the spoken academic discourse in English-taught programmes in countries where English is neither the local language nor that of most of the international students. ELF research questions the importance of nativeness, studies standard language use, prioritises communicability among multilinguals and is usually studied in connection to issues of language proficiency and language attitudes (Björkman 2011; Jenkins 2011; Mauranen 2012; Kuteeva 2014). The second is integrating content and language learning in HE (ICLHE), emerging from the Maastricht conference, while the third is parallel language use. Not free from criticism (Airey and Linder 2008), parallel language use has been used by some Scandinavian scholars (Pecorari, Shaw, Irvine et al. 2011; Pecorari, Shaw, and Malmström et al. 2011; Kuteeva 2014) to describe settings with dual uses of Swedish and English, where lecturers speak in their L1 and where the textbooks and other reference books are in English. In parallel-language teaching, incidental language learning (i.e. unplanned learning resulting from other activities) is tacitly assumed and exposure to a foreign language is thought to promote motivation and attention in learners. When Pecorari, Shaw, Irvine et al. (2011) carried out a large-scale survey to investigate parallellanguage teaching in Swedish universities, they found out that teachers paid little or no attention to planning exposure to English, specified no English language outcomes in formal course documentation, and expressed concerns about their abilities to teach in English. At the same time, though, these lecturers hoped their students would acquire some English during their courses. In brief, the authors think that if no preconditions for incidental learning have deliberately been created, incidental learning may not take place. Given that the teachers in their study do not have any specific linguistic learning outcomes in mind, the authors point to the need to differentiate parallel-language teaching from CLIL and trace parallel language use roots back to previous elite university settings 'in which students were expected to read in several languages' (Pecorari, Shaw, Irvine et al. 2011, 57).

As can be seen, the presence of language learning aims and stakeholders' language proficiency seems central to CLIL and consequently they are recurrent themes in CLIL research at tertiary level. Klaassen and Bos $(2010,74)$ studied Danish lecturers' average language proficiency and concluded that unless a systematic approach was used to learn and develop disciplinary and academic discourse among students and lecturers, the academic language proficiency of participants would hardly improve. In another study on the effect of language proficiency on university students (Aguilar and Muñoz 2014), lecturers' insufficient proficiency was also pointed to as an important difficulty to be overcome. Insufficient language proficiency is seen to affect instruction in other ways. For example NNS students and lecturers are seen to speak at a slower speaking rate and in a more formal register when they speak in English than whey they speak in their L1 (Hincks 2010; Thøgersen and Airey 2011). Additionally, NNS teachers lecturing in English are reportedly said to lose level of detail and use few examples or asides (Jensen and Thøgersen 2011) and a smaller number of questions has also been noted in EMI (Airey and Linder 2008; Airey 2012). As to students' problems, in Swedish degree programmes (Benson et al. 2008) and in a Spanish business studies master's programme (Ruiz-Garrido and Palmer-Silveira 2008) students were found to have few problems with 
the language and understand lectures well whilst in Northern European countries Hellekjaer (2010) and Evans and Morrison (2011) report superficial understanding of lectures and problems with lecture comprehension, sometimes caused by lecturers' poor English and pronunciation.

Research on language learning aims associated with CLIL methodology tends to yield similar results. Pedagogical aspects like scaffolding and interactive methodology including frequent use of questions, feedback and discussions instead of teacher-fronted lecturing are of paramount importance (Lister 2007), yet some lecturers seem to feel 'English language proficiency is the only skill that needs refreshment' (Klaassen 2008, 33) and they show little interest in receiving methodological training (Benson et al. 2008; Aguilar and Rodríguez 2012; Fortanet-Gómez 2013). Lecturers' refusal to correct English (Airey 2011) and to teach English (Airey 2012) stands in agreement with the scant explicit mention of language learning goals in course descriptions (Pecorari, Shaw, Irvine et al. 2011). This view, however, has been partly challenged by Unterberger (2012), who found out that one-third of course descriptions in an Austrian university do include language learning aims, such as presentation, negotiation and discussion skills and development of specialised vocabulary knowledge. Worth mentioning is that research analysing lecturers taking on the role of language teachers and focusing on form (Costa 2012; Hynninen 2012) reveals a close connection with content expertise and Costa (2012) contends that even though lecturers refuse to teach English, they use pre-emptive focus on form, thus rendering EMI closer to ICLHE. Yet, it is not clear if minimal adjustments may be mostly subservient to making content understandable, stemming from didacticism (i.e. lecturers struggling to convey content with clarity). A very interesting account of lecturers' refusal to teach English and the low amount of tandem courses (content and language specialists working together) is found in Airey (2012). In this work, he studies physics lecturers' attitudes to the development of disciplinary learning and disciplinary language skills in both English and Swedish. He posits that the clash between physics and English teaching may play a role, in particular if the language specialist comes from a discipline with a horizontal knowledge structure (as in the humanities) and the content teacher comes from a discipline with a hierarchical knowledge structure (such as engineering, physics or medicine). Physics lecturers in this study believed that the choice of language of instruction was unproblematic because in physics, disciplinary knowledge is taken as agreed and is not seen to change when language changes. Thus, content and language teachers' familiarity with the ontological and epistemological assumptions of each other's disciplines may be a recommended requirement for a desirable cooperation between them.

\section{Methodology}

In this study, CLIL is going to be used in its stricter sense, loyal to the $L$ and $I$ in its acronym, that is, instruction in a foreign language where content and language are integrated, and where both language and content learning outcomes are catered for. On the other hand, EMI is seen to encompass pre- and non-CLIL varieties in terms of Greere and Räsänen (2008) and is here equated with the type of context where content is the priority and where no assessment of students' English competence is made because no language learning outcomes are acknowledged. The idea of making such distinction and surveying university lecturers in this respect arose from discussion that the researcher in this study had with some engineering lecturers during an in-service teacher training, where it turned out that they welcomed EMI and flatly refused CLIL. Their refusal to teach English closed the door to any other modality, such as tandem teaching with language specialists (Adjunct CLIL). As in other countries such as Austria and Sweden (Airey 2012; Unterberger 2012), the universities in this study do not offer tandem teaching and ESP-EAP courses are optional courses, either because of sharp cuts in ESP classes or because of watertight boundaries between disciplines (Fortanet-Gómez and Räisänen 2008; Unterberger 2012).

Having two categories inevitably implies overgeneralising because halfway between the two foci, other in-between orientations with different degrees of attention given to linguistic goals may be found. These would include settings where, content being the only goal, a few specific scaffolding techniques are sometimes offered in passing to facilitate content learning or push students into 
full participation. These techniques tend to include online provision of key term glossaries, oral presentations, enhanced visibility of key concepts or occasional readings in English. Because it is hypothesised that lecturers resort to these strategies for didactic purposes (i.e. interest in conveying content) and never to deliberately teach English, in this work a context where English learning is never a learning goal (even if some serendipitous adjustments are present) is considered EMI.

This study draws on both quantitative and qualitative methods. First, a 24-item questionnaire was administered to bilingual (Catalan-Spanish) engineering lecturers from three different Catalan universities in Spain. Two master coordinators provided this researcher with a list of lecturers who taught in English. The questionnaire was sent via email to 62 content lecturers who were lecturing in English and 41 engineering lecturers ( 34 male, 7 female) answered, which points to the limited scope of the work. The sample in this study in fact represents one university, as $93 \%$ of the lecturers came from the same technical university. As to the other $7 \%$, they were part-time teachers who used to teach in the technical university and were at that time teaching in one or two nearby universities. The questionnaire had to be answered on a 5 -Likert scale and started with a few biodata questions, so the survey was not anonymous. The respondents' average age was $42.4,65 \%$ were senior lecturers, $14.6 \%$ professors and the rest were assistant lecturers. Lecturers were asked to read the following definitions of CLIL and EMI below before answering the 24 questions:

CLIL is defined as integrated learning of both content and language and implies content and language are priorities with clearly specified goals. Both content and English language are assessed. Methodology is accommodated to teach (and evaluate) language and content. Full collaboration between content and language specialists. Usually associated with the focus used in primary and secondary education but does not exclude HE by any means; in the latter case, sometimes ICLHE is used.

$E M I$ implies that content - which is given in English - is the priority. Some incidental language learning is expected due to exposure but without any specific language learning goals. English (language) learning is not assessed. Scarce or no collaboration between content and English specialists. There may be little accommodation in terms of methodology, only to guarantee comprehension and understanding of content.

It must be noted that in the case of the universities under study, the recent internationalisation policies basically consist in the introduction of content courses in English and in certification of students' foreign language competence (usually English) and since the main university under study was beginning its internationalisation process, most lecturers were not dealing with highly international classrooms.

The questionnaire surveys were statistically analysed with Minitab statistical software in order to find the mean, the frequencies (Table 1) and if some questions were related in any way. Once the questionnaires were analysed, those with slightly different replies were sorted out. As the questionnaires were not anonymous, it was possible to identify and contact the six lecturers ( $14.6 \%$ of lecturers) representing different views, mostly over the telephone. These lecturers taught electronics, power control, reactor physics, statistics and manufacturing technologies and had more than two years of experience in teaching in English. In the interview, the first four questions were recast to let them expand on their views on their English-medium teaching. The semi-structured interview was therefore based on inquiring Why did you reply ... ? in items 1, 2, 3 and 4, backbones of this study. The researcher sometimes interrupted them with some improvised open questions (How can this affect $x$ ? How can this be solved? Why do you think so?). In the interview, lecturers elaborated on their survey responses and mentioned other related issues. The subsequent analysis of the notes taken during the interviews yielded four main themes that are going to be described in the following section.

\section{Results}

Quantitative results are going to be discussed first. Lecturers' experience in lecturing in English ranged between 0.6 and 5 years and approximately half of them had received specific training $(51.2 \%)$ while the other half $(48.7 \%)$ had not. No significant relationship was found ( $p$-value: 0.00$)$ between a given type of score and position, years of experience or specific training received. 
Table 1. Statistical results $(M=$ mean, $F=$ Frequency, e.g. $F 1=$ frequency in scale 1$)$.

\begin{tabular}{ccccc}
\hline 1 & 2 & 3 & 4 & 5 \\
\hline Completely disagree & Disagree & $\begin{array}{l}\text { Uncertain (neither } \\
\text { agree nor disagree) }\end{array}$ & $\begin{array}{l}\text { Agree } \\
\text { agree }\end{array}$ & $\begin{array}{l}\text { Completely } \\
\text { agree }\end{array}$ \\
\hline
\end{tabular}

\begin{tabular}{|c|c|c|c|c|c|c|}
\hline & Mean & F1 (\%) & $\begin{array}{l}\mathrm{F} 2 \\
(\%)\end{array}$ & F3 (\%) & $\begin{array}{l}\mathrm{F} 4 \\
(\%)\end{array}$ & $\begin{array}{l}\text { F5 } \\
(\%)\end{array}$ \\
\hline 1. I think the focus I follow is CLIL. & 1.44 & 63.4 & 31.7 & 2.4 & 2.4 & 0.0 \\
\hline 2. I think the focus I follow is EMI. & 4.68 & 0 & 0 & 2.4 & 26.8 & 70.7 \\
\hline 3. I feel at ease with my focus. & 4.22 & 0 & 2.4 & 9.7 & 51.2 & 36.6 \\
\hline 4. I'd like to change focus. & 1.98 & 41.4 & 24.4 & 29.2 & 4.8 & 0 \\
\hline $\begin{array}{l}\text { 5. I'd say the focus mostly followed in my faculty is } \\
\text { CLIL. }\end{array}$ & 2.23 & 24.4 & 41.4 & 24.4 & 2.4 & 7.3 \\
\hline $\begin{array}{l}\text { 6. I'd say the focus mostly followed in my university is } \\
\text { CLIL. }\end{array}$ & 2.23 & 17 & 48.7 & 26.8 & 4.9 & 2.4 \\
\hline $\begin{array}{l}\text { 7. I assess English learning separately from content } \\
\text { learning (e.g. language learning is 10\% of the total } \\
\text { mark) and students know. }\end{array}$ & 1.68 & 63.4 & 17.1 & 12.2 & 2.4 & 4.8 \\
\hline 8. I do not assess English (language learning). & 4.17 & 14.6 & 0 & 4.9 & 14.6 & 65.8 \\
\hline $\begin{array}{l}\text { 9. It is in fact more difficult to get good marks in my } \\
\text { subject for students with a poor level of English. }\end{array}$ & 3.05 & 4.8 & 21.9 & 43.9 & 21.9 & 7.3 \\
\hline $\begin{array}{l}\text { 10. I think the focus that better fits Spanish/Catalan } \\
\text { universities is CLIL. }\end{array}$ & 2.52 & 12.2 & 31.7 & 43.9 & 9.7 & 2.4 \\
\hline $\begin{array}{l}\text { 11. I think the focus that better fits Spanish/Catalan } \\
\text { universities is EMI. }\end{array}$ & 3.67 & 4.9 & 4.9 & 34.1 & 46.3 & 9.7 \\
\hline $\begin{array}{l}\text { 12. I think the focus that better fits Spanish/Catalan } \\
\text { universities is neither EMI nor CLIL. }\end{array}$ & 2.11 & 43.9 & 24.3 & 9.7 & 19.5 & 2.4 \\
\hline $\begin{array}{l}\text { 13. I think that a course where the local language } \\
\text { (Catalan/Spanish) is always used and where } \\
\text { recommended or compulsory readings, and/or } \\
\text { lecturers' slides are in English can be considered a } \\
\text { course 'taught in English'. }\end{array}$ & 1.86 & 31.7 & 56.1 & 4.9 & 7.3 & 0 \\
\hline $\begin{array}{l}\text { 14. I think that Catalan will eventually lose within this } \\
\text { new context of internationalisation and lecturing in } \\
\text { English. }\end{array}$ & 2.34 & 21.9 & 39 & 21.9 & 14.6 & 2.4 \\
\hline $\begin{array}{l}\text { 15. I think that the internationalisation drive will stay } \\
\text { with us for a long time; it's not a temporary trend. }\end{array}$ & 4.07 & 4.9 & 9.7 & 7.3 & 31.7 & 46.3 \\
\hline $\begin{array}{l}\text { 16. I think my university has clear policies on what } \\
\text { internationalisation is. }\end{array}$ & 2.75 & 2.4 & 34.1 & 43.9 & 17 & 2.4 \\
\hline $\begin{array}{l}\text { 17. My university distinguishes internationalisation in } \\
\text { bachelor's programmes (Internationalisation at Home, } \\
\text { laH, addressed to local students) from } \\
\text { internationalisation at master's (addressed to both a } \\
\text { local and foreign audience). }\end{array}$ & 3.05 & 4.9 & 12.2 & 48.8 & 31.7 & 2.4 \\
\hline $\begin{array}{l}\text { 18. Lecturers following CLIL should receive a specific } \\
\text { training. }\end{array}$ & 4.18 & 2.4 & 7.3 & 7.3 & 36.6 & 46.3 \\
\hline $\begin{array}{l}\text { 19. Lecturers following EMI should receive a specific } \\
\text { training. }\end{array}$ & 3.30 & 4.8 & 19.5 & 31.7 & 34.1 & 9.7 \\
\hline $\begin{array}{l}\text { 20. As in many European universities, lecturers willing } \\
\text { to lecture in English should possess C } 1 \text { (advanced level, } \\
\text { according to CEFR). }\end{array}$ & 3.98 & 2.4 & 2.4 & 14.6 & 53.6 & 26.8 \\
\hline $\begin{array}{l}\text { 21. I think that when my master students start a } \\
\text { master's programme they are already proficient in } \\
\text { both general English and in technical/academic } \\
\text { English, written and spoken. }\end{array}$ & 2.72 & 12.2 & 24.4 & 41.1 & 19.5 & 2.4 \\
\hline $\begin{array}{l}\text { 22. As in many European universities, the university } \\
\text { should require students to at least possess B.2.2 } \\
\text { (according to CEFR) before the start of a master's } \\
\text { programme. }\end{array}$ & 4.21 & 0 & 2.4 & 9.7 & 53.6 & 34.1 \\
\hline $\begin{array}{l}\text { 23. I'd like to receive specific teacher training on CLIL/ } \\
\text { EMI methodology (my choice) }\end{array}$ & 3.22 & 17 & 7.3 & 21.9 & 43.9 & 9.7 \\
\hline $\begin{array}{l}\text { 24. I'd like to receive English training (e.g. to improve } \\
\text { my spoken fluency, to shift from an informal to a more } \\
\text { academic/formal register, etc.). }\end{array}$ & 3.72 & 7.3 & 7.3 & 17 & 41.4 & 26.8 \\
\hline
\end{tabular}


The analysis of questions 1 (I think the focus I follow is CLIL) and 2 (I think the focus I follow is EMI) refers to the first research question and shows that EMI is the focus teachers follow (mean 4.68); the low deviation (SD 0.51) confirms scant disparity. Because EMI and CLIL are not considered to be blackand-white answers, and particularly in order to see if their EMI incorporated some features of CLIL, like explicit language assessment, questions 1 and 2 were contrasted with questions 7 and 8 on English assessment. Difficulty in delivering the same content in English as in their L1 within the same span of time is an oft-heard argument, as well as their self-perceived insufficient language proficiency, so it was thought that inquiring about language assessment would hint at this. The answers to questions one and two highly correlate with their answers in questions 7 and 8, corroborating that those who follow EMI do not assess their students' English learning. A lecturer who disagreed later said in the interview that penalising misspellings in technical jargon for him implied some assessment, though he could not specify in what percentage of the final mark. In question 3 (I feel at ease with my focus) we find that $87.8 \%$ feel at ease with EMI and only $9.7 \%$ is uncertain. Worth noting is that although in question 4 (I'd like to change focus) most respondents disagree, $29.2 \%$ of them was uncertain. Tangentially related to this is what counts as CLIL-EMI and what not. They disagree with the statement I think that a course where the local language (Catalan/Spanish) is always used and where recommended or compulsory readings, and/or lecturers' slides are in English can be considered a course 'taught in English' (question 13), pointing to their spread assumption that a requisite is that English must be the lecturer's language of instruction.

Most teachers disagree with the statement that CLIL is the modality chosen in their faculty (question 5 , mean $=2.23$ ) and in their university (question 6 , mean $=2.23$ ). Both questions highly correlate $(0.82$, see Figure 1$)$, which suggests that when teachers think that CLIL is not followed in their faculty, they also think the same is true for their university. However, if one bears in mind that in questions 1 and 4 teachers reported EMI was their focus, the amount of uncertain answers in questions 5 and 6 is surprisingly high - implying there are teachers who follow EMI but who think that 'the others' may follow less EMI and more CLIL.

Lecturers' views on English proficiency, internationalisation and training (second research question) were obtained in the remaining items. As to questions on the required English proficiency, it can be seen that teachers agree (question 20, mean 3.98) with the idea of demanding C1 (advanced level within the Common European Framework of Reference for languages) for teachers and B.2.2 (upper-intermediate level) for students before accessing a master's programme (question 22, mean 4.21). In addition, lecturers seem uncertain (mean 3.05) when they are asked It is in fact more difficult to get good marks in my subject for students with a poor level of English. Their answers deploy a normal distribution, although in a related question (21) they do not seem to think students are proficient in general English and academic English when starting a master's programme (mean

\section{Dotplot of 5 (faculty: CLIL); 6 (university: CLIL)}

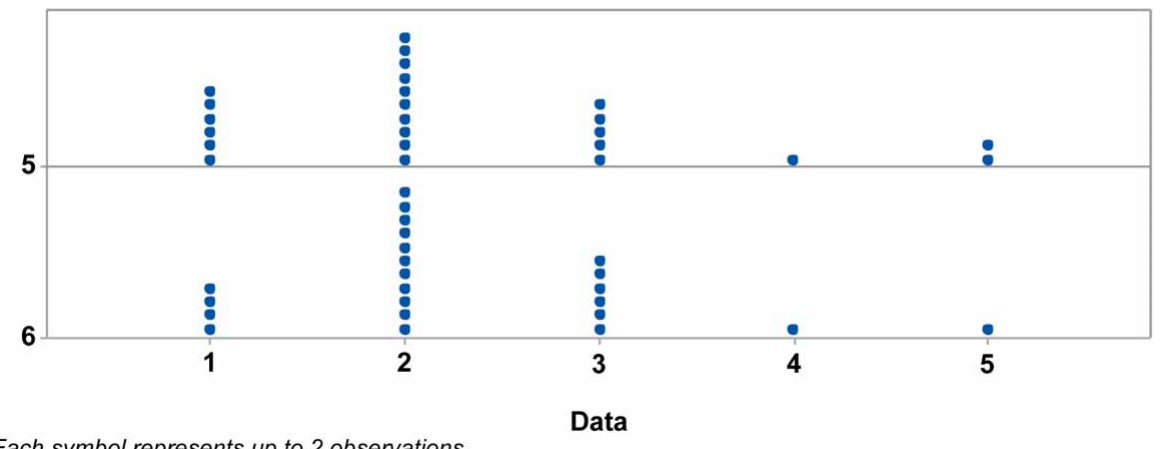

Each symbol represents up to 2 observations.

Figure 1. Replies to questions 5 and 6. 
2.72). Their uncertainty is a symptomatic finding that hints at their lack of factual information and their scant reflection on their courses. It was later confirmed in the interviews that lecturers do not reflect much upon their teaching in English. In fact, none of them had asked their students to do a placement test to find out their students' average level.

Teachers' views on the most appropriate focus for university and country as well as on university policy towards internationalisation were also probed. Questions 10 and 11 basically measure the same, but in the opposite way - in question 10 (CLIL is more appropriate) low scores are found (mean 2.52) while question 11 (EMI is more appropriate) has higher scores (mean 3.57). Thus, we can conclude that teachers tend to think EMI fits better. Questions 12 (mean 2.11) and 14 (mean 2.34), though, show close replies and, as seen in Figure 2, the teacher who agrees (and has high scores) with question 12 (I think the focus that better fits Spanish/Catalan universities is neither EMI nor CLIL) also agrees with the statement I think that Catalan will eventually lose within this new context of internationalisation and lecturing in English (question 14). Figure 2 shows how similar the replies to questions 12 and 14 were in contrast with diametrically opposed replies in questions 10 and 11. These results partly stand in agreement with Baker's bunker attitude (Baker 1995) to protect the minority language in front of the invasion of a majority language and point to lecturers' concern for the minority language (Catalan) within the Englishisation of universities (Coleman 2006).

Information about teachers' views on internationalisation understood as the introduction of CLILEMI was obtained from questions 15, 16 and 17. Teachers agree with the idea that the internationalisation drive is not a temporary fashion (mean 4.07), although it must be remembered that these are self-selected lecturers who may hold different views from lecturers who do not teach in English and thus did not participate in the study. On the other hand, they are rather uncertain in questions 16 (I think my university has clear policies on what internationalisation is, mean 2.75) and 17 (My university distinguishes internationalisation in bachelor's programmes-Internationalisation at Home, laH, addressed to local students - from internationalisation at master's - addressed to both a local and foreign audience, mean 3.05). These questions were later raised in the interviews, where lecturers admitted not knowing much about their university's policies, nor about laH.

Finally, teachers agree that specific training is necessary when following CLIL (question 18) and EMI (question 19) though they agree more clearly in the case of CLIL. The difference between both means is significant (4.18 and 3.30 respectively, with $p$-value $=0.00$ ), which reflects their belief that CLIL, more than EMI, requires specific training. When they are inquired on the type of

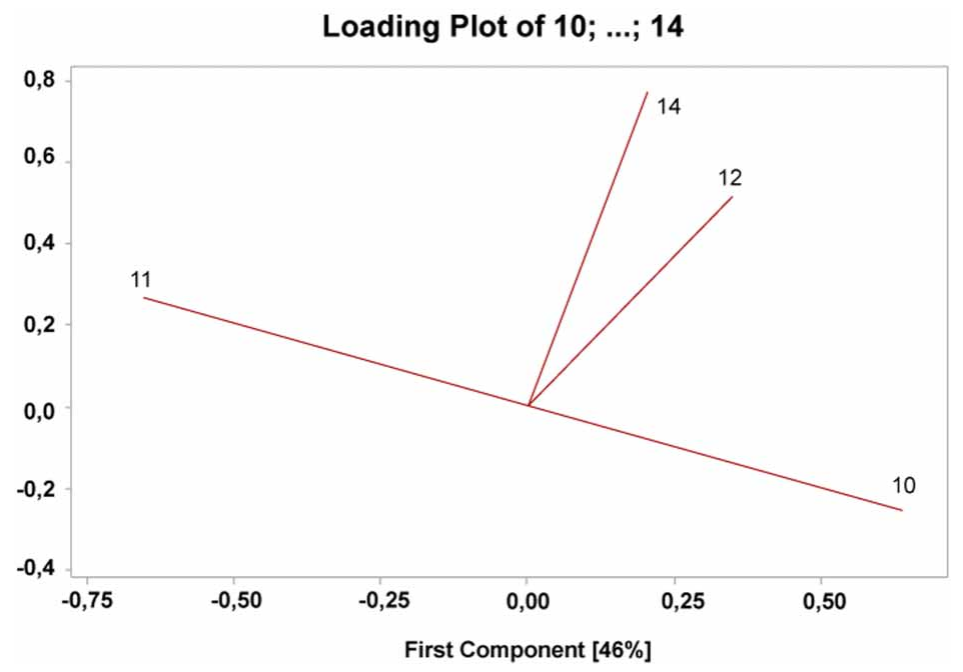

Figure 2. Comparison of replies to questions 10, 11, 12 and 14. 
instruction they would like to receive in question 23 (I'd like to receive specific teacher training on CLIL/ EMI methodology, emphasis on methodology) and 24 (I'd like to receive English training, for example, to improve my spoken fluency, to shift from an informal to a more academic/formal register, emphasis on linguistic training), the results are similar (23: mean 3.22 and 24: mean 3.72). Their interest in linguistic rather than methodological training resonates with previous research (Klaassen 2008; Aguilar and Rodríguez 2012; Fortanet 2013). It must be noted, however, that the high deviation in questions 23 (SD 1.23) and 24 (SD 1.14) reveals significant disparity among respondents. In order to see if there was any correlation between lecturers' beliefs regarding the need of specific training and the modality they followed, Pearson correlation coefficient was applied first between questions 1 and 18, and then between questions 2 and 19. There was a weak correlation (Pearson's $r=$ 0.200698 ) between 1 and 18 and no correlation (Pearson's $r=-0.0283587$ ) between 2 and 19; that is, lecturers who gave a low score in 1 and in 2 did not give a low score in 18 and 19, respectively.

\section{Qualitative results}

After analysing the questionnaire, six lecturers who had replied differently in items 1 and 2 (I think the focus I follow is EMI/CLIL) and items 3 and 4 (I feel at ease with my focus; I'd like to change focus) were chosen and interviewed drawing on the questionnaire (e.g. In the survey you said that your approach is EMI and that you do not want to change to CLIL. Why?). During the interview, the researcher sometimes interrupted with more improvised 'How/Why' questions. Then, from the notes taken during interviews, recurrent themes were identified and grouped such that four main issues emerged: (i) EMI and CLIL, (ii) the key factors for a successful EMI, (iii) the internationalisation drive and (iv) benefits, problems and challenges.

The first theme referred to their modality and their (un)willingness to shift to CLIL. By and large, they justify their unwillingness to change in terms of their perceived poor English (How should I? My English is not good enough) and the limited time they have to fulfil their perceived duty (I have my hands full with teaching content). When the teachers who had ticked uncertainty in the survey were inquired, they put forward two reasons. They stated that they might shift to CLIL provided the extra workload was acceptable, as EMI is for them less demanding, and only if the university rewarded their extra effort. The other reason refers to their belief they are already having English in mind: providing glossaries of terms is something I do, so to some extent this is language integration, said one lecturer. It appears these teachers feel that paying special attention to key technical vocabulary places their focus halfway between EMI and CLIL. The importance placed by university lecturers on technical vocabulary has been documented (Pecorari, Shaw, Irvine et al. 2011) and these results substantiate it is a widespread belief.

Because the first lecturer interviewed suggested telling EMI and CLIL apart, the other lecturers were asked about the convenience of making the distinction formally. All six teachers welcomed the idea of distinguishing EMI and CLIL and publishing official information on learning outcomes and teaching duties in their course description files. They thought that distinguishing and tagging both foci would allow lecturers and the university to make a fine-tuned offer to students, something students would like. When they were asked why they thought explicit tagging of their teaching duties could be useful, they specified it would be more a transparent and faithful description of reality, aligning themselves with the (language free) teaching duties for an EMI teacher. Teachers also thought that students with a proficient level of English would probably prefer EMI while, in their opinion, less proficient students would probably prefer CLIL. One teacher even suggested following CLIL for undergraduates and EMI for master students. Lecturers shared the idea that offering CLIL would encourage Spanish students to enrol in CLIL courses because local students are in general less proficient in English than Erasmus ones. Interestingly, lecturers always mentioned the benefits for students but never for them.

The second theme, key factors in EMI, in fact revolved around quality performance and assurance and around what could, or should, the university do to guarantee quality in EMI. The key issue for all 
teachers was that students and lecturers should have a very good command of English and, most specifically, they stressed the compelling need for teachers to master technical jargon in English. Accordingly, they thought that teaching in English called for continuous improvement and that university policy should prioritise content courses in English and implement some follow-up to assure a minimum level of quality. This was crucial if their university wanted to play a role in the European landscape. Among the suggested actions to check that EMI was effectively carried out satisfactorily, most mentioned that the university should offer them assistance in translating and preparing their materials in English and provision of English conversation courses to improve their general communication skills in English. Because their choice was EMI, they were unenthusiastic about being trained in CLIL methodology at all. Worth noting here is that they never mentioned ESP-EAP courses, which may be indicative they can be overshadowed, even menaced, if EMI is offered not only 'on top of', but also 'instead of'. Tandem teaching with ESP teachers was therefore not contemplated. The separation of ESP courses from content courses partly resonates with the adjunct function of ESP courses in other countries (Unterberger 2012). To finish with the second issue, other ideas to guarantee quality were enhanced mobility and a white book on the present situation (amount of courses in English, analysis of masters fully taught in English, etc.). As English proficiency seemed so important to teachers, the researcher elicited information related to item 9 (e.g. If English proficiency is so important for you, how do think a poor level of English affects students' marks?). They conceded they did not know and showed interest in analysing the ratio good marks-English level in their courses.

The third was the internationalisation process. This trend was interpreted as the main motivation behind the introduction of EMI. In line with Swedish lecturers (Pecorari, Shaw, Irvine et al. 2011), Spanish teachers do not hesitate to confer a crucial role on English as the language of science and technology; they think that English is a must in engineering and that internationalisation is not an outlived fashion, although EMI courses may be overplayed, as one lecturer said: the souffle will go down with the passing of time and common sense will prevail. If a teacher is better at communicating his stuff in his L1, quality shouldn't be sacrificed for English. Nevertheless, none of the lecturers criticised or downplayed the internationalisation process; instead, they stressed the importance of their university becoming more international. Internationalisation proved to be closely related to the advantageous internationalisation of their professional career and was therefore associated with benefits, the following topic.

Recognition of the main benefits and challenges in EMI was the fourth broad theme. To begin with, all teachers mentioned the positive outcomes for students; with EMI, students could practise their English skills, enhance their employability and use EMI as some preparation prior to mobility. As to their own benefits, lecturers were satisfied with their lecturing through English and they positively valued their experience for different reasons: their improved English fluency, their course being more international and the presence of more Erasmus students enlivening their classes. A serendipitous benefit was their international aura, some added value in their curriculum that can only open up new opportunities, in their opinion. Lecturers showed interest mostly in English, thought that other foreign languages were secondary priorities and stressed they had volunteered to lecture in English because they wanted to improve their English. Thus, their overall self-assessment was positive because they noted that after the first experience, their confidence and fluency in English had boosted in ways they had never thought before. Worth noting is a teacher's reflection on the communicative side of lecturing; he concluded that, after all, technical terminology was not so difficult and that CLIL and EMI teachers alike should have excellent communication skills in English. At this point the researcher inquired about the challenges and whether they believed their students were learning English with them. For all teachers but one, their main challenge was to improve their English fluency, which was the reason why teachers flatly refused any responsibility as English teachers. They felt slightly ashamed of their insufficient fluency, yet they also believed that it was beneficial for students to learn specialised terminology in English. Lecturers had never considered they also taught disciplinary literacy and although some acknowledged how important it is for students to be familiar with disciplinary literacy, others were baffled about the extra load they inadvertently had 
on their shoulders, showing lack of faith in their skills or unwillingness. In this sense, the engineering lecturer profile sharply contrasts with the more open-minded profile of humanities and social science subject teachers (Erlenawati 2011). For these lecturers, the most important problem was inadequate English proficiency because without a proficient level of English, communication and transmission of content could be in jeopardy. The risk that the added difficulty in following a course in English deters local students from enrolling, because many still see CLIL/EMI as a problem, was also a repeated theme. Finally, the 'student composition' factor was also highlighted in that teaching in English at a Spanish university seemed more natural if a few Erasmus students were present.

\section{Discussion and concluding remarks}

This study aimed at delving into engineering lecturers' views on their English-taught courses. Answering the first research question, quantitative analyses show that EMI is the only modality in the engineering master programmes the lecturers were teaching. None of the 41 engineering lecturers were following CLIL, mostly because they refuse to teach English, as already documented (Airey 2012). Thanks to qualitative data, we know that EMI is their choice because their perceived teaching duties are content specific and language free, because their self-assessed English proficiency is insufficient and because of the positive outcomes for them, namely internationalised university/course classroom and boosted confidence in oral fluency. A recurrent topic when they articulate their EMI choice is English proficiency, which is a positive outcome and a challenge at the same time, both for students and lecturers. Yet, this study has two shortcomings. First, even though it could be argued that results might differ had the definition of EMI and CLIL been different, findings like their refusal to integrate language or their lack of reflection on their EMI would most probably remain the same. These lecturers do not want to teach or assess English and some of them consider that glossaries and oral presentations is a way of integrating language. Second, the results are based on a small corpus comprising only engineering lecturers, so more research is necessary to determine if this trend can be generalised in the EHE, particularly in other European engineering and business masters programmes where EMI is most frequent (Wächter and Maiworm 2008, 2014). It is here suggested that a white book on EHE internationalisation in this respect could lay the groundwork for better-informed policies, years after the onset of internationalisation.

Tapping their choice into their beliefs about CLIL/EMI was the second research question. Qualitative results converge with quantitative ones in that both reveal that most lecturers see EMI not as a problem or a right but as resource (García 2009). Engineering lecturers do not seem to prefer EMI driven by beliefs in a multilingual and multicultural Europe but mostly by an instrumental and utilitarian conception of education and their academic career. English is their medium of research dissemination and choosing English as the medium of instruction is rather a means subservient to the higher-order aim of boosting and internationalising their career and university. Lecturers think students are also obvious beneficiaries because they are better prepared to work as engineers in a globalised world, a reported benefit of multilingual education (Skutnabb-Kangas 1995; García 2009).

Another important finding is that having given some thought on EMI and CLIL, lecturers were certain about the benefits of separating both. For these lecturers, the explicit tagging of both modalities would result in better-informed students, raised awareness about the nature of lectures in English, alignment with one option, coherent adoption of the teaching duties and learning outcomes accordingly and a more efficient allocation of human resources, that is, more proficient lecturers sensitive to methodology would adopt a CLIL focus aimed at less proficient students who need the scaffolding provided by CLIL. At the same time, if EMI implies having proficient students, EMI lecturers may feel more at ease if their proficiency is similar or superior to that of their students. Yet, one feels lecturers favour official tagging because they are going to choose EMI, thus dispensing with all language teaching duties. An implication that can be derived from this finding is that on the one hand lecturers' suggestion of tagging EMI and CLIL distinctively would require institutional and administrative changes. This may help universities present themselves and their educational 
goals more accurately and truthfully. From an academic viewpoint, explicit and sanctioned tagging should never be conceived of as a straitjacketing measure but rather as an attempt to clarify learning goals and teaching duties. On the other hand, it may be 'dangerous for Europe to allow language policy to be left to laissez faire market forces' (Phillipson, cited in García 2009, 206).

A further revealing finding was that lecturers had in fact not reflected on their English-medium lecturing and that they had little or no information about internationalisation policies or laH, which made them uncertain about different issues. For example, lecturers had never reflected on their responsibility in teaching disciplinary literacy and they did not know their students' average proficiency, nor how/whether low proficiency negatively affected students' performance. Likewise, although the lecturers in the study prefer linguistic training over CLIL methodological training, it should be remembered that the disparity in their replies suggests that some may be open to incorporating articulated pedagogic adjustments, if properly trained. Likewise, $29.2 \%$ of lecturers was uncertain in question four in the survey (I'd like to change focus) because, according to the lecturers interviewed, they would like to be (more) supported and rewarded by their university and because they felt they were in fact integrating language with their provision of terminology glossaries. To conclude, the finding regarding the low level of relevance these lecturers attach to language learning has clear implications for future in-service lecturer training, for institutional policies in internationalised universities, and lastly for the challenges for English language specialists. It seems reasonable to claim that EMI lecturers should be trained and made aware about minimal necessary pedagogic adaptations that even a good EMI requires. If the priority is mere functional competence, English language specialists could then take over to cater for student (and teacher) proficiency and accuracy, ensuring quality in the internationalised EHE and guaranteeing that good practices in CLIL and EMI are catered for.

\section{Disclosure statement}

No potential conflict of interest was reported by the author.

\section{Funding}

This study has benefited from funding obtained through the project FFI2012/35834 awarded by the Ministry of Sciency and Economy of Spain.

\section{References}

Aguilar, M., and C. Muñoz. 2014. "The Effect of Proficiency on CLIL Benefits in Engineering Students in Spain." International Journal of Applied Linguistics 24: 1-18.

Aguilar, M., and R. Rodríguez. 2012. "Implementing CLIL at a Spanish University. Lecturer and Student Perceptions." The International Journal of Bilingual Education and Bilingualism 15: 183-197.

Airey, J. 2011. "Talking about Teaching in English: Swedish University Lecturers' Experiences of Changing Teaching Language." Iberica 22: 35-54.

Airey, J. 2012. "I Don't Teach Language'. The Linguistic Attitudes of Physics Lecturers in Sweden." In Integrating Content and Language in Higher Education, edited by U. Smit and E. Dafouz, 64-79. AlLA Review 25. Amsterdam: John Benjamins.

Airey, J., and C. Linder. 2008. "Bilingual Scientific Literacy? The Use of English in Swedish University Science Courses." Nordic Journal of English Studies 7: 145-161.

Baker, C. 1995. Attitudes and Language. 2nd ed. Clevendon: Multilingual Matters.

Benson, C., S. Brunsberg, R. Duhs, D. Minugh, and Ph. Shaw. 2008. "Preparing for International Masters Degrees in Stockholm University and RIT in Stockholm." In ESP in European Higher Education, edited by I. Fortanet and Ch. Räisänen, 267-282. Amsterdam: John Benjamins.

Björkman, B. 2011. "English as a Lingua Franca in Higher Education: Implications for EAP." Iberica 22: 79-100.

Bonnet, A. 2012. "Towards an Evidence Base for CLIL." International CLIL Research Journal 1: 66-78. http://www.icrj.eu/14/ article7.html.

Bruton, A. 2011. "Is CLIL so Beneficial or Just Selective? Re-evaluating Some of the Research." System 39: 523-532. 
Coleman, J. 2006. "English-medium Teaching in European Higher Education." Language Teaching 39: 1-14.

Costa, F. 2012. "Focus on Form in ICLHE lectures in Italy." In Integrating Content and Language in Higher Education, edited by U. Smit and E. Dafouz, 30-47. AILA Review 25. Amsterdam: John Benjamins.

Costa, F., and L. D'Angelo. 2011. "CLIL: A Suit for All Seasons?" Latin American Journal of Content and Language Integrated Learning 4: 1-13.

Dafouz, E., M. Camacho, and E. Urquía. 2014. "'Surely they can't do as well': A Comparison of Business Students' Academic Performance in English-medium and Spanish-as-first-language-medium Programmes" Language and Education 18: 223-236.

Dafouz, E., and U. Smit. 2014. "Towards a Dynamic Conceptual Framework for English-medium Education in Multilingual University Settings." Applied Linguistics 1-20.

Doiz, A., D. Lasagabaster, and J. Sierra. 2011. "Internationalisation, Multilingualism and English-medium Instruction." World Englishes 30: 345-359.

Erlenawati, S. 2011. "Academic Staff Response to International Students and Internationalising the Curriculum: The Impact of Disciplinary Differences." International Journal for Academic Development 16: 45-57.

Eurydice. 2006. Content and Language Integrated Learning (CLIL) at School in Europe. Brussels: Eurydice European Unit.

Evans, S., and B. Morrison. 2011. "Meeting the Challenges of English-medium Higher Education: The First-year Experience in Hong Kong." English for Specific Purposes 30: 198-208.

Fortanet-Gómez, I. 2013. CLIL in Higher Education. Towards a Multilingual Language Policy. Bristol: Multilingual Matters.

Fortanet-Gómez, I., and Ch. Räisänen. 2008. ESP in European Higher Education. Amsterdam: John Benjamins.

García, O. 2009. Bilingual Education in the 21st Century. Chichester: Wiley-Blackwell.

Greere, A., and A. Räsänen. 2008. Year One Report. LANQUA subproject on Content and Language Integrated Learning: Redefining 'CLIL'_Towards Multilingual Competence. http://www.lanqua.eu/files/Year1Report_CLIL_ForUpload_ WithoutAppendices_0.pdf.

Hellekjaer, G. O. 2010. "Language Matters: Assessing Lecture Comprehension in Norwegian English-medium Education." In Language Use and Language learning in CLIL Classrooms, edited by Ch. Dalton-Puffer, T. Nikula, and U. Smit, $233-258$. Amsterdam: John Benjamins.

Hincks, R. 2010. "Speaking Rate and Information Content in English Lingua Franca Oral Presentations." English for Specific Purposes 29: 4-18.

Hynninen, N. 2012. "ICL at the Micro Level." In Integrating Content and Language in Higher Education, edited by U. Smit and E. Dafouz, 13-29. Amsterdam: John Benjamins.

Jenkins, J. 2011. "Accommodating (to) ELF in the International University." Journal of Pragmatics 43: 926-936.

Jensen, C., and J. Thøgersen. 2011. "Lecturing Undergraduate Science in Danish and in English: A Comparison of Speaking Rate and Rhetorical Style." Journal of English for Specific Purposes 30: 209-221.

Klaassen, R. 2008. "Preparing Lecturers for English-medium Instruction." In Realizing Content and language Integration in Higher Education, edited by R. Wilkinson and V. Zegers, 32-42. Maastricht: Maastricht University.

Klaassen, R., and M. Bos. 2010. "English Language Screening for Scientific Staff at Delft Universit of Technology." HermesJournal of Language and Communication Studies 45: 61-75.

Kuteeva, M. 2014. "The Parallel Language Use of English and Swedish: The Questions of 'Nativeness' in University Policies and Practices." Journal of Multilingual and Multicultural Development 35: 332-344.

Lasagabaster, D., J. M. Cots, and G. Mancho-Barés. 2013. "Teaching Staff's Views about the Internationalisation of Higher Education: The Case of Two Bilingual Communities in Spain." Multilingua 32: 751-778.

Lister, R. 2007. Learning and Teaching Languages through Content. Amsterdam: John Benjamins.

Mauranen, A. 2012. Exploring ELF: Academic English Shaped by Non-native Speakers. Cambridge: Cambridge University Press.

Pecorari, D., P. Shaw, A. Irvine, and H. Malmström. 2011. "English for Academic Purposes at Swedish Universities: Teachers' Objectives and Practices." Ibérica 22: 55-77.

Pecorari, D., P. Shaw, H. Malmström, and A. Irvine. 2011. "English Textbooks in Parallel-language Tertiary Education." TESOL Quarterly 45: 313-333.

Pérez-Cañado, M. L. 2012. "CLIL Research in Europe: Past, Present, and Future." International Journal of Bilingual Education and Bilingualism 15: 315-341.

Ruiz-Garrido, M. F., and J. C. Palmer-Silveira. 2008. "Content Learning in Business Communication: A Teaching Experience within New European Framework." In ESP in European Higher Education, edited by I. Fortanet and Ch. Räisänen, 147-164. Amsterdam: John Benjamins.

Ruiz de Zarobe, Y., J. M. Sierra, and F. Gallardo, eds. 2011. Content and Foreign Language Integrated learning. Bern: Peter Lang.

Skutnabb-Kangas, T. 1995. Multilingualism for All. Lisse: Swets and Zeilinger.

Smit, U., and E. Dafouz. 2012. "Integrating Content and Language in Higher Education. An Introduction to Englishmedium Policies, Conceptual Issues and Research Practices across Europe." In Integrating Content and Language in Higher Education, edited by U. Smit and E. Dafouz, 1-12. AlLA Review 25. Amsterdam: John Benjamins.

Thøgersen, J., and J. Airey. 2011. "Lecturing Undergraduate Science in Danish and in English: A Comparison of Speaking Rate and Rhetorical Style." English for Specific Purposes 30: 209-221. 
Unterberger, B. 2012. "English-medium Programmes at Austrian Business Faculties." In Integrating Content and Language in Higher Education, edited by U. Smit and E. Dafouz, 80-100. Amsterdam: John Benjamins.

Unterberger, B., and N. Wihelmer. 2011. "English-medium Education in Economics and Business Studies. Capturing the Status Quo at Austrian Universities." International Journal of Applied Linguistics 16: 90-110.

Wächter, B., and F. Maiworm. 2008. English-taught Programmes in European Higher Education. ACA Papers on International Cooperation in Education. Bonn: Lemmens.

Wächter, B., and F. Maiworm, eds. 2014. English-taught Programmes in European Higher Education. The State of Play in 2014. ACA Papers on International Cooperation in Education. Bonn: Lemmens. 